\title{
NEK7 promotes gastric cancer progression as a cell proliferation regulator
}

\author{
Yi-Ke Lii ${ }^{1+}$, Xiao-Ran Zhu ${ }^{2,3,5+}$, Yue Zhan ${ }^{3,6}$, Wen-Zhen Yuan ${ }^{2,3,4^{*}}$ and Wei-Lin Jin ${ }^{2,3,5^{*}}$ (1)
}

\begin{abstract}
Background: Gastric cancer is one of the most common malignant tumors of the digestive system. However, its targeted therapy develops at a slow pace. Thus, exploring the mechanisms of the malignant behavior of gastric cancer cells is crucial to exploit its treatment. Mammalian never-in-mitosis A (NIMA)-related kinases (NEKs) are considered to play a significant role in cancer cell proliferation. However, no study has reported on NIMA family proteins in gastric cancer.

Methods: Bioinformatics analysis was employed to clarify the expression patterns of NEK1-NEK11 and their effects on prognosis. The effects of NEK7 on immune infiltration and NEK7 related pathways were also analyzed. At the cell level, 5-ethynyl-2-deoxyuridine, cell cycle, and Cell Counting Kit-8 assays were utilized to clarify the effect of NEK7 on gastric cancer cell proliferation. A mouse subcutaneous model revealed the regulating effect of NEK7 on gastric cancer cell proliferation in vivo.

Results: Bioinformatics analysis revealed that NEK7 is upregulated in gastric cancer and is related to poor prognosis. NEK7 is also related to T-stage, which is closely associated with cell proliferation. Further analysis showed that NEK7 was correlated with infiltration of multiple immune cells as well as gastric cancer-related pathways. Cell experiments indicated the promoting effect of NEK7 on cell proliferation, while the absence of NEK7 could lead to inhibition of gastric cancer proliferation and G1/S arrest.
\end{abstract}

Conclusion: NEK7 exerts a regulatory effect on cell proliferation and is closely related to tumor immune infiltration.

\section{Background}

Cancer is a leading cause of death and a huge barrier to extending life expectancy worldwide. According to the statistics published on $C A$ by the American Cancer Society in 2021, gastric cancer is the sixth leading cause of cancer-related deaths, and approximately one million new cases of gastric cancer were recorded, while more than 780 thousand deaths were reported in 2020 [1]. For all tumors, immortalization is the most basic characteristic, so targeting cell proliferation is an essential concept

\footnotetext{
*Correspondence: yuanwzh@|zu.edu.cn; Idyy_jinwl@|zu.edu.cn; weilinjin@yahoo.com

${ }^{\dagger}$ Yike Li and Xiaoran Zhu have equal contributions

${ }^{2}$ The First School of Clinical Medicine, Lanzhou University, Lanzhou 730000, People's Republic of China

Full list of author information is available at the end of the article
}

in cancer therapy for decades. However, the targeted therapy for gastric cancer develops slowly. Thus, shedding new light on the mechanism of gastric cancer cell proliferation is significant to develop new therapeutic methods and early screening.

The proliferation of eukaryotic cells, including cancer cells, relies on mitosis with a stable cell cycle. The stability of the cell cycle is maintained by many regulatory proteins, especially by kinases [2]. Abnormal expression of cell cycle-related kinases could accelerate the cell cycle and result in inappropriate proliferation. Mammalian never-in-mitosis A (NIMA)-related kinases (NEK proteins) are a group of positive regulatory proteins of the cell cycle that could regulate microtubules and promote mitosis. Expressions of NEK proteins are higher in various malignant tissues than in normal tissues. original author(s) and the source, provide a link to the Creative Commons licence, and indicate if changes were made. The images or other third party material in this article are included in the article's Creative Commons licence, unless indicated otherwise in a credit line to the material. If material is not included in the article's Creative Commons licence and your intended use is not permitted by statutory regulation or exceeds the permitted use, you will need to obtain permission directly from the copyright holder. To view a copy of this licence, visit http://creativecommons.org/licenses/by/4.0/. The Creative Commons Public Domain Dedication waiver (http://creativeco mmons.org/publicdomain/zero/1.0/) applies to the data made available in this article, unless otherwise stated in a credit line to the data. 
Moreover, ectopic expressions and genetic variations of NEK proteins are higher in tumor tissues. These unusual expressions of NEK proteins could lead to cell cycle dysregulation and eventually cancer [2].

In 1975, Morris investigated mitotic mutants of Aspergillus nidulans and found that Aspergillus nidulans never goes through mitosis A [3]. NIMA kinases were named after nidulans protein kinases that are encoded by the NIMA gene. They are a kind of serine-threonine kinases that are needed during mitosis [3, 4]. Since its discovery, 11 genetically different NIMA kinases (NEK1-NEK11) were identified in most eukaryotes, including humans. As regards the function of NEK proteins, previous studies have shown that NEK2, NEK6, NEK7, and NEK9 mainly participate in G2-M key point regulation, promote the maturity of the centrosome, and influence chromosome condensation as well as spindle formation in mitosis, while NEK1, NEK10, and NEK11 are involved in DNA damage response $[5,6]$.

We analyzed the expressions of NIMA kinases and their effects on prognosis synthetically and found that only NEK7 is upregulated in gastric cancer and exerted a significant effect on gastric cancer prognosis. A previous study showed that NEK7 is activated by the direct connection of NEK9 through allosteric and non-allosteric mechanisms in mitosis. Moreover, NEK7 controls phosphorylation of kinesin KIF11 and recruitment to the centrosome; as a result, the centrosome separates [7]. Thereafter, NEK7 participates in spindle assembly through phosphorylated heat shock protein NUP98 and controls cytokinesis through the regulation of motile kinesin Mklp2 as well as kinesin KIF14 [8]. Salem et al. found that lack of NEK7 could cause death in late embryonic and early postnatal periods as well as severe developmental retardation through the development and analysis of NEK7-defected mice. Meanwhile, mouse embryonic fibroblasts tended to present lagging chromosome, micronucleus formation, and cytokinesis failure [9].

Recent research presented that NEK7 was mainly connected with NLRP3 inflammasome. NEK7 could activate inflammasome NLRP3 to produce numerous polykaryocytes and apoptotic cells, which are closely related to inflammation, and then cause inflammation in the body $[10,11]$. The effects of the NEK7-NLRP3 axis on diabetic retinal degeneration, systemic lupus erythematosus, and gout have already been evaluated [12-15]. Meanwhile, Eisa et al. found that the expression of NEK7 could promote cell division in cancer [16]. Zhang et al. found that NEK7 is frequently upregulated in retinoblastoma cell lines, while NEK7 knockdown by virus-mediated RNA interference could significantly inhibit cell growth as well as colony formation and arrest in the G0/G1 phase
[17]. Zhou et al. also found that the expression of NEK7 is significantly higher in hepatoma cell lines than in normal liver cell lines. Furthermore, virus-mediated NEK7 silencing could inhibit the growth of hepatocellular carcinoma cell lines and tumor cells on the xenotransplantation model in immunodeficient mice [18]. Although those studies have revealed the connection between NEK7 and malignancies, NEK7 has not yet been reported in gastric cancer.

\section{Methods}

\section{Cell culture}

Two human gastric cancer cell lines MKN-45, MGC-803, and HEK-293 T were purchased from Beyotime Biotechnology (Shanghai, China). All cells were cultured in a medium containing $90 \% \mathrm{DMEM}+10 \% \mathrm{FBS}+1 \% \mathrm{P} / \mathrm{S}$.

\section{Construction of NEK7 knockdown cell line}

Plasmids that expressed shRNA-1 (CATTCTCGAAGA GTCATGCATAGAGATATAAAACCAGCTAA) and shRNA-2 (GAAGGCCTTACGACCGGATATGGG CTATAATACATTAGCCA) were designed. The lentiviral plasmids were constructed by the Public Protein/Plasmid Library.

After screening, shRNA-1 was used to construct stable knockdown cell lines. The lentivirus packaging kit (Gmeasy-40, Genomeditech) was then utilized.

\section{Protein extraction}

Cells were cultured in 100-mm Petri dish until their density reached 70-90\%. Radioimmunoprecipitation medium (P00103C, Beyotime Biotechnology) was used to extract total protein from cultured cells. Then, cells were boiled for $10 \mathrm{~min}$ after adding loading buffer (CoWin Biosciences, MA, USA).

Reverse-transcription polymerase chain reaction (RT-PCR) MKN-45 and MGC-803 were treated with Trizol and RNA was extracted following the manufacturer's instructions. The RNA was dissolved in $10-100 \mu \mathrm{l}$ of diethylpyrocarbonate-treated water, and dilution was appropriately performed for quantification. The RNA was measured by UV spectrophotometry and reverse transcribed into cDNA using a reverse transcription kit.

RNA expression was assayed by real-time PCR set to $95{ }^{\circ} \mathrm{C}$ for $30 \mathrm{~s}, 55{ }^{\circ} \mathrm{C}$ for $30 \mathrm{~s}$, and $72{ }^{\circ} \mathrm{C}$ for $7 \mathrm{~min}$ and repeated for 40 circulations. Glyceraldehyde 3-phosphate dehydrogenase (GAPDH) was utilized as an endogenous control. All quantitative RT-PCR reactions were performed three times independently. The relative RNA 
expression levels were calculated using the $2^{-\triangle \triangle \mathrm{Ct}}$ method.

\section{Western blot (WB)}

Protease inhibition was used to extract total protein from cell lysis of MKN-45 and MGC-803. Bicinchoninic acid protein assay kit was used to measure protein concentration. Protein was separated by sodium dodecyl sulfate-polyacrylamide gel electrophoresis in appropriate concentration and transformed onto polyvinylidene fluoride membranes. After blocking for $1 \mathrm{~h}$ at $4{ }^{\circ} \mathrm{C}$ using trisbuffered saline with Tween ${ }^{\circledR} 20$ (TBST) brewed skim milk powder, the membrane was incubated overnight with the anti-NEK7 (ab13514, abcam, UK) antibody and antiGAPDH (ab8245, abcam) antibody, which was diluted to an appropriate concentration. Then, after washing, the membrane was incubated with the second antibody at $4{ }^{\circ} \mathrm{C}$ for at least $1 \mathrm{~h}$ and washed by TBST three times. The anti-CDK4 (Cat No. 11026-1-AP), anti-CCND2 (Cat No. 10934-1-AP), anti-KIF3A (Cat No. 13930-1-AP), antiAKT3 (Cat No. 21641-1-AP), and anti-PRKG1 (Cat No. 21646-1-AP) antibodies were purchased from the Proteintech Group (IL, USA). Signals were detected using a chemiluminescence system (SensiCapture imaging system, Peiqing Technology Co. LTD, China).

\section{5-Ethynyl-2-deoxyuridine (EdU) to stain proliferating cells} EdU staining was utilized to analyze MKN-45 and MGC803 cells with normal and downregulation of NEK7 expression. The EdU buffer and cell medium were mixed in a ratio of 1:1000 and added into the plate $(2 \mathrm{ml}$ in each well) and then incubated at $37{ }^{\circ} \mathrm{C}$ for $2 \mathrm{~h}$. The medium was discarded, and after washing, phosphate-buffered saline (PBS) with $4 \%$ paraformaldehyde was added $(2 \mathrm{ml}$ each well) for cell fixation $\left(37^{\circ} \mathrm{C}, 30 \mathrm{~min}\right)$. Then, the cells were permeabilized with $0.5 \%$ Triton X-100 and cultured for $10 \mathrm{~min}$. The EdU staining solution was added, and the nuclei were stained with 4',6-diamidino-2-phenylindole. The results could be visualized under a fluorescence microscope.

\section{Cell Counting Kit-8 (CCK-8) assay}

MKN-45 and MGC-803 cells were suspended and seeded into 96-well plates. After being incubated at $37^{\circ} \mathrm{C}$ for $24 \mathrm{~h}, 10 \mu \mathrm{l}$ of CCK-8 solution (US Everbright Inc., China) was added to each well. The absorbance was measured by a microplate reader at $450 \mathrm{~nm}$ after being incubated for $4 \mathrm{~h}$ in a dark environment.

\section{Flow cytometry}

The treated cells were collected and fixed with chilled $75 \%$ ethanol at $-20{ }^{\circ} \mathrm{C}$ overnight or longer. After ethanol was being discarded, cells were washed twice with PBS and then stained with cell cycle and apoptosis kit (C6031, UE, China) at room temperature for $30 \mathrm{~min}$. Moreover, $400 \mu \mathrm{L}$ of PBS or $1 \times$ binding buffer was added to each tube. The selection between PBS and $1 \times$ binding buffer was decided based on the apoptosis method and cell type. Then, cell apoptosis was analyzed immediately through flow cytometry. YF488-Annexin V was excited at $488 \mathrm{~nm}$. The fluorescence emission spectrum was detected at $530 \mathrm{~nm}$ (fluorescein isothiocyanate channel), and the emission spectrum of the PI channel was detected at $617 \mathrm{~nm}$. Cell cycle analysis was performed on the flow cytometry (FACS LSRII, BD Bioscience, China).

\section{Animal studies}

shNC and shNEK7 cells were collected and suspended in pre-cooled PBS and subcutaneously injected into the mice $\left(1 \times 10^{7} / 100 \mu\right.$ l per mouse). Twelve mice were used in total, and the negative control $(n=6)$ and experimental $(n=6)$ groups included randomly selected mice (room condition: temperature $20-26{ }^{\circ} \mathrm{C}$, relative humidity $40-70 \%$, light and darkness alternate every $12 \mathrm{~h}$ ) The mice were sacrificed at the end of the experiment (day 26). The removed tumors were used in immunohistochemistry (IHC) staining and WB. The experiments were approved by the Ethics Committee of the First Hospital of Lanzhou University (LDYYLL2021-179).

\section{Bioinformatics analysis and statistics}

The differential gene expression in tumor and normal tissues and the correlation between protein expression and clinical prognosis of patients with gastric cancer were analyzed by GEPIA (http://gepia.cancer-pku.cn/) tool. The correlation analysis between NEK7 expression and immune infiltration level was performed using TIMER 2.0 (http://timer.cistrome.org/). GraphPad Prism 8.0 software (GraphPad Software Inc., La Jolla, CA) was also used to analyze the results. As for the quantitative PCR assay, the relative RNA expression levels were calculated using the $2^{-\triangle \triangle \mathrm{Ct}}$ method ("p $<0.05$, *** $\mathrm{p}<0.01$, NS, not significant).

\section{Results}

NEK7 is highly expressed in gastric cancer cells and may be implicated in poor prognosis

We synthetically analyzed the expression of NIMA kinases (NEK1-NEK11) (Fig. 1a-k) in gastric cancer tissues and normal tissues. The correlation between NEK protein expression and clinical prognosis of patients with gastric cancer was also analyzed (Fig. 1l-v). The results showed that only the expression level of NEK7 


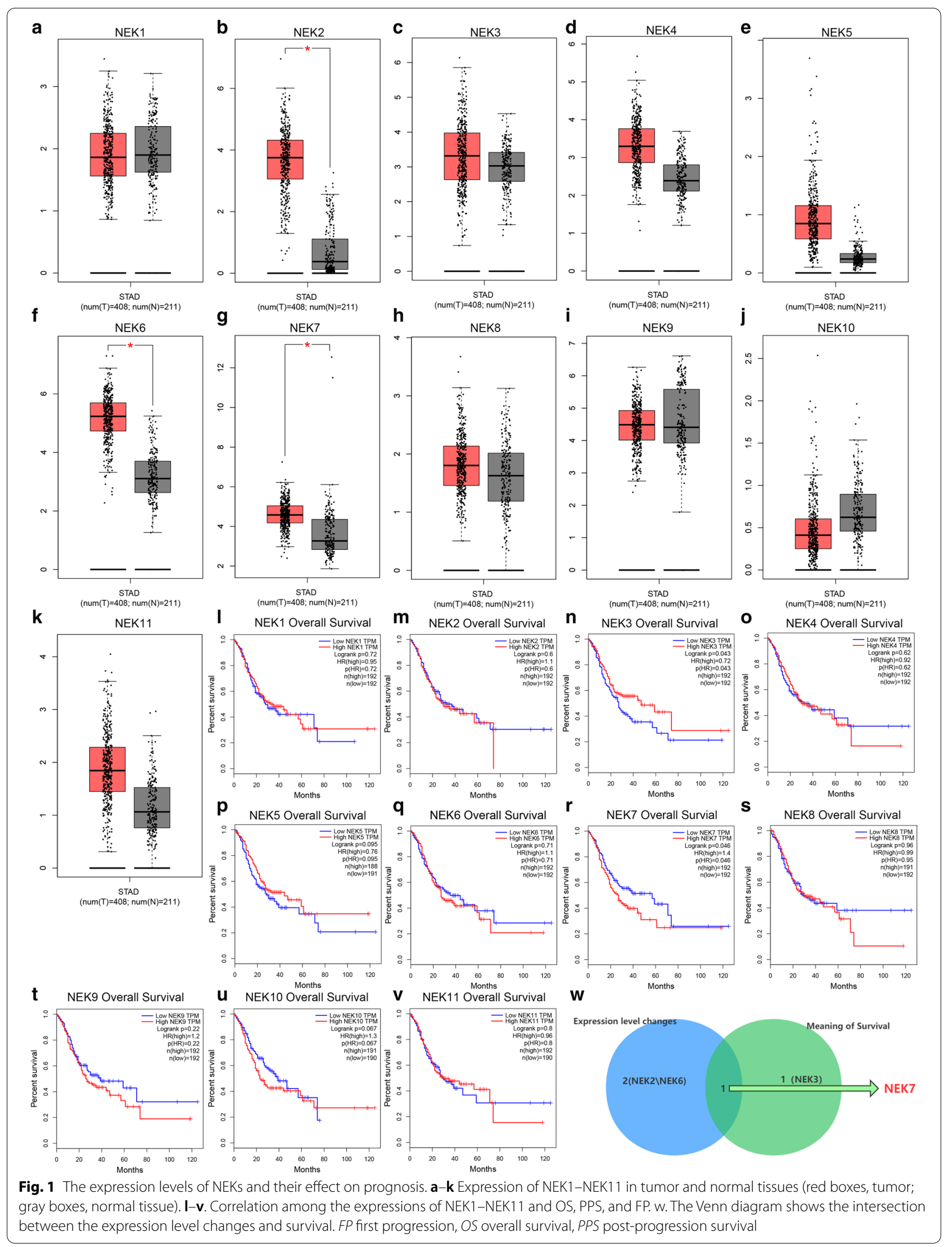


was upregulated in gastric cancer $(|\operatorname{LogFC}|>1, \mathrm{p}<0.01$ was significant) and predicted poor survival prognosis (Fig. 1w).

\section{NEK7 is related to gastric cancer staging}

We obtained RNA-seq (RNA-sequencing) data and the corresponding clinical information of 375 gastric cancer samples in The Cancer Genome Atlas Stomach Adenocarcinoma (TCGA-STAD) dataset to analyze the a
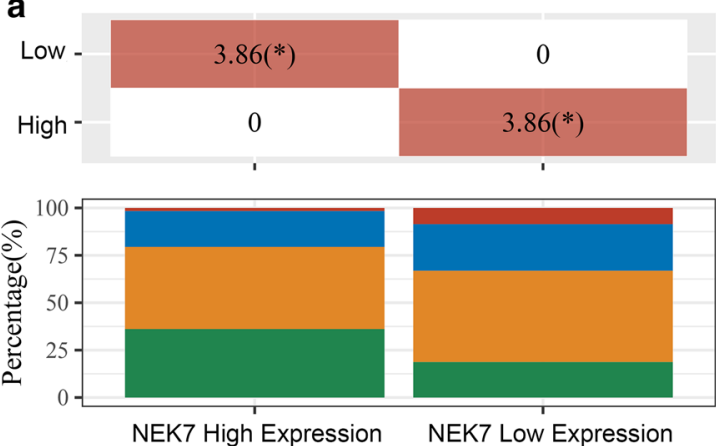

$\begin{array}{lllll}\mathrm{T} 1 & \mathrm{~T} 2 & \mathrm{~T} 3 & \mathrm{~T} 4\end{array}$

C
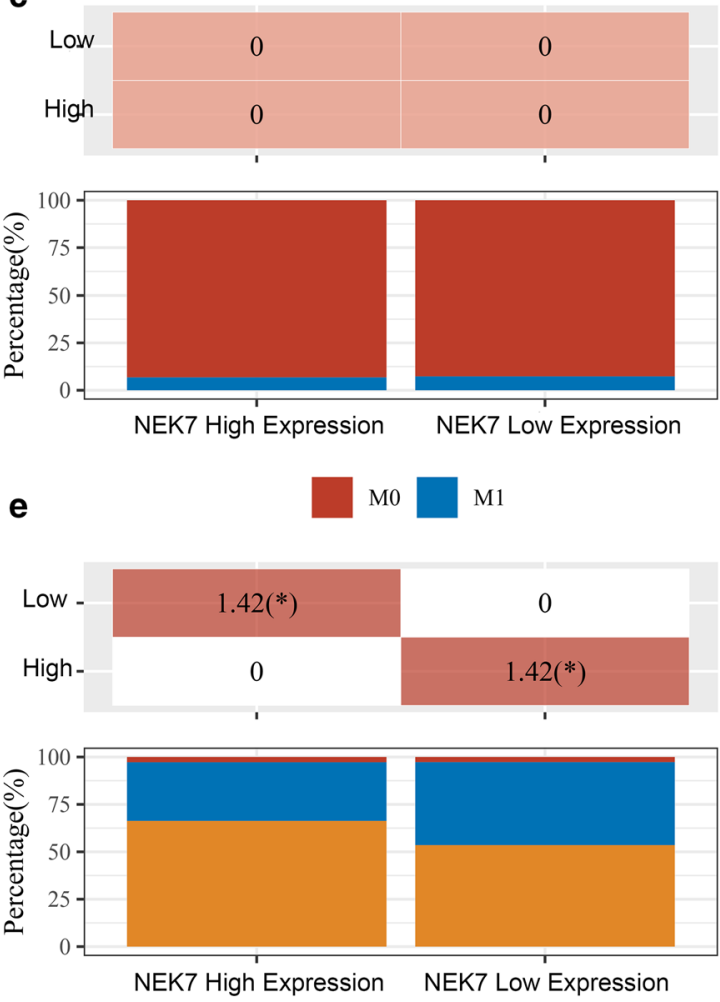

G1

G2

G3
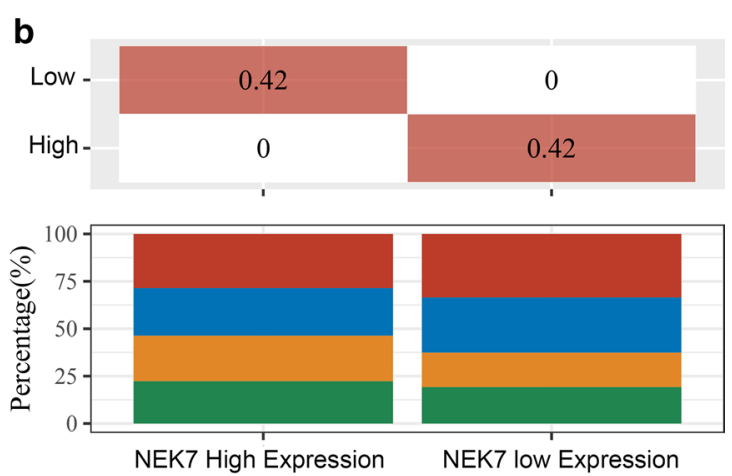

N0 $\quad$ N1 $\quad$ N2

d
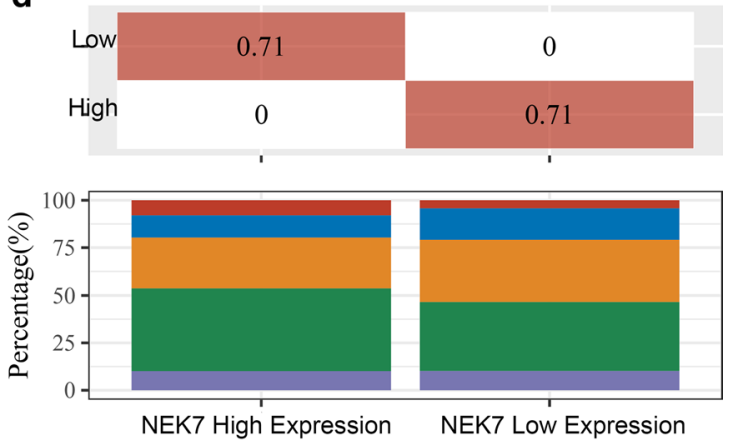

f

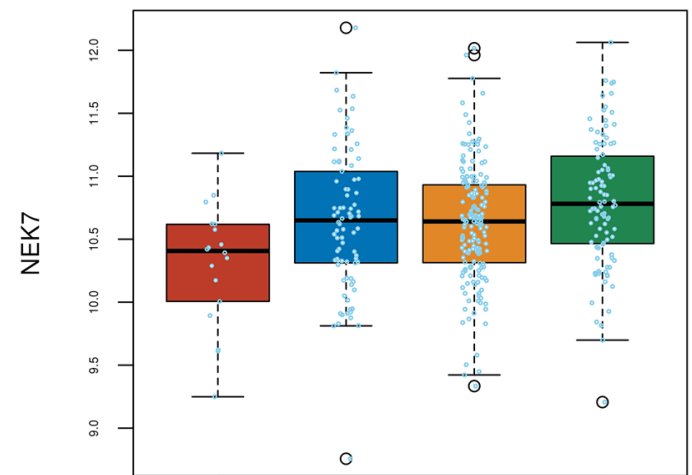

$\begin{array}{llllll}\mathrm{T} 1 & \mathrm{~T} 2 & \mathrm{~T} 3 & \mathrm{~T} 4\end{array}$

Fig. 2 NEK7 expression effects the TNM staging and pathological grading. a-d The stacked diagram shows the percentage of each stage of the TNM staging at different NEK7 expression levels. The horizontal axis represents the samples with high or low NEK7 expressions, and the vertical axis represents clinical information contained in the corresponding grouped samples analyzed with $p$-value by chi-square test. For significance, the value is - $\log 10$ ( $p$-value). *Significant difference $(p<0.05)$. a Percentage of $\mathrm{pT}$ staging. b Percentage of pN staging. $\mathbf{c}$ Percentage of pM staging. $\mathbf{d}$ Percentage of PTNM staging. $\mathbf{e}$ The stacked diagram shows the percentage of pathological grading at different NEK7 expression levels. $\mathbf{f}$ The box plot shows NEK7 expression levels in samples of different pT stages 
relationship between NEK7 expression level and clinicalpathological grading (Fig. 2e) and staging (Fig. 2a-d). The expression level of NEK7 in the late pT stage is higher than that in the early stage (Fig. 2f). The results indicated that the high expression of NEK7 may be implicated in the late $\mathrm{T}$ stage and high pathological grade. Complete clinicopathological information is listed in Table 1.

\section{NEK7 is associated with immune cell infiltration}

TIMER 2.0 was used to analyze the effect of NEK7 on immune infiltration. The expression of NEK7 is positively related to the infiltration of Treg cells (Fig. 3a), macrophages (Fig. 3b), monocytes (Fig. 3c), neutrophils (Fig. 3d), and M2 macrophages (Fig. 3e) in gastric cancer, even if it has no distinct correlation with infiltration of M1 macrophages (Fig. 3f). Overall, the results demonstrated that immune cell infiltration could be affected by NEK7.

\section{NEK7 is related to an important pathway of cell proliferation}

By using RNA-seq data of gastric cancer from TCGA, we analyzed genetic correlation and obtained a gene map positively and negatively associated with NEK7 (Fig. 4a-c). Then, enrichment analysis on GO-BP and Kyoto Encyclopedia of Genes and Genomes (KEGG) (Fig. $4 \mathrm{~d}-\mathrm{f}$ ) were performed. The results of the GO-BP analysis indicated that NEK7 was closely related to cellcell adhesion via plasma membrane adhesion molecule pathway and multicellular organismal signaling pathway. Besides, NEK7 was positively related to the cell junction pathway. These results demonstrated that NEK7 was significant in regulating multicellular signaling and intracellular proliferation-related pathways. Moreover, we clarified the relationship between NEK7 and the aforementioned pathways by gene set enrichment analysis (GSEA) (Fig. 4g). Similar to the results of the KEGG analysis, GSEA showed that NEK7 was positively related to the cGMP-PKG signaling pathway, focal adhesion, extracellular matrix-receptor interaction, and Hedgehog signaling pathway. These pathways were found to be closely related to cancer progression. Moreover, using WB assay, the levels of the cGMP-PKG signaling pathway-related proteins (CCND4 and KIF3A) and Hedgehog signaling pathway-related proteins (AKT3 and PRKG1) after NEK7 administration were downregulated (Additional file 1: Fig. S1a). The results demonstrated that NEK7 downregulation could influence cGMP-PKG and Hedgehog signaling pathways through the downregulation of related proteins. The bioinformatics analysis showed the same results (Additional file 1: Fig. S1b).

\section{NEK7 could promote proliferation of gastric cancer cells in vitro}

NEK7-downregulated in vitro gastric cancer models were established based on MGC-803 and MKN-45 cells. WB and quantitative RT-PCR analysis were conducted to detect the effect of NEK7 silencing (Fig. 5a, b). Then, CCK-8 assay (Fig. 5c), flow cytometry (Fig. 5d, e), and EDU assay (Fig. 5f, g) were utilized to investigate the effect of NEK7 on gastric cancer cell proliferation. The results showed that downregulation of NEK7 could inhibit proliferation of gastric cancer cells, reduce the proportion of neoplastic gastric cancer cells, and lead to cell cycle G1/S arrest. Besides, we detected the expression levels of cell cycle-related proteins such as CDK4 and CCND2 with NEK7 downregulation through western blot (WB) assay (Additional file 1: Fig. S1a). The results showed that CCND2 was downregulated, but CDK4 expression was not significantly different. The bioinformatics analysis by gene expression profiling interactive analysis (GEPIA) showed the same results (Additional file 1: Fig. S1b) The aforementioned results show that NEK7 could promote gastric cancer cell proliferation.

NEK7 could promote gastric cancer proliferation in vivo

Further, we focused on MKN45 cells and injected MKN45-shNC and MKN45-shNEK7 subcutaneously in mice (Fig. 6a). The growth of the subcutaneous tumor was monitored (Fig. 6b, c). The mice were sacrificed and dissected after 26 days. The removed subcutaneous tumors were weighed. Then, WB was performed to detect the expression level of NEK7 (Fig. 6d). Moreover, IHC was utilized to detect the expression levels of NEK7 and MKI-67 (Fig. 6e). The results indicated that the tumor volume and mass of the experimental group injected with stable MKN45-shNEK7 cells were significantly lower than those in the control group injected with MKN45-shNC cells. WB and IHC showed that the NEK7 expression levels of the experimental group were significantly lower than those of the control group. In brief, these results demonstrate that NEK7 could promote gastric cancer cell proliferation in vivo. Ultimately, NEK7 could promote gastric cancer cell proliferation both in vitro and vivo. 
Table 1 Patients' clinicopathological information

\begin{tabular}{|c|c|c|c|}
\hline Characters & NEK7-high & NEK7-low & P-value \\
\hline \multicolumn{4}{|l|}{ Status } \\
\hline Alive & 103 & 125 & \\
\hline Dead & 85 & 62 & 0.022 \\
\hline \multicolumn{4}{|l|}{ Age } \\
\hline Mean (SD) & $65.7(10.3)$ & $65.9(11.1)$ & \\
\hline Median [MIN, MAX] & $67[35,90]$ & $67.5[39,90]$ & 0.856 \\
\hline \multicolumn{4}{|l|}{ Gender } \\
\hline Female & 71 & 63 & \\
\hline Male & 117 & 124 & 0.474 \\
\hline \multicolumn{4}{|l|}{ Race } \\
\hline Asian & 28 & 46 & \\
\hline Black & 6 & 5 & \\
\hline White & 130 & 108 & \\
\hline Islander & & 1 & 0.04 \\
\hline \multicolumn{4}{|l|}{ pT_stage } \\
\hline $\mathrm{T} 1$ & 1 & 4 & \\
\hline $\mathrm{T} 1 \mathrm{~b}$ & 2 & 10 & \\
\hline $\mathrm{T} 2$ & 22 & 36 & \\
\hline T2a & 6 & 3 & \\
\hline $\mathrm{T} 2 \mathrm{~b}$ & 6 & 7 & \\
\hline T3 & 78 & 90 & \\
\hline T4 & 18 & 12 & \\
\hline T4a & 33 & 13 & \\
\hline $\mathrm{T} 4 \mathrm{~b}$ & 14 & 10 & \\
\hline $\mathrm{TX}$ & 8 & & \\
\hline T1a & & 2 & 0.003 \\
\hline \multicolumn{4}{|l|}{ pN_stage } \\
\hline NO & 50 & 61 & \\
\hline $\mathrm{N} 1$ & 44 & 53 & \\
\hline N2 & 42 & 33 & \\
\hline N3 & 12 & 14 & \\
\hline N3a & 26 & 16 & \\
\hline N3b & 1 & 5 & \\
\hline NX & 12 & 4 & 0.058 \\
\hline \multicolumn{4}{|l|}{ pM_stage } \\
\hline MO & 165 & 165 & \\
\hline M1 & 12 & 13 & \\
\hline$M X$ & 11 & 9 & 0.888 \\
\hline \multicolumn{4}{|l|}{ pTNM_stage } \\
\hline IA & 3 & 11 & \\
\hline $\mathrm{IB}$ & 19 & 18 & \\
\hline$\|$ & 12 & 15 & \\
\hline$\| \mathrm{A}$ & 11 & 24 & \\
\hline$\| \mathrm{B}$ & 27 & 22 & \\
\hline$\| I I A$ & 34 & 26 & \\
\hline$\| I \mid B$ & 24 & 28 & \\
\hline IIIC & 24 & 11 & \\
\hline IV & 19 & 19 & \\
\hline I & & 2 & \\
\hline
\end{tabular}


Table 1 (continued)

\begin{tabular}{|c|c|c|c|}
\hline Characters & NEK7-high & NEK7-low & P-value \\
\hline III & & 3 & 0.036 \\
\hline \multicolumn{4}{|l|}{ Grade } \\
\hline G1 & 5 & 5 & \\
\hline $\mathrm{G} 2$ & 56 & 81 & \\
\hline G3 & 120 & 99 & \\
\hline GX & 7 & 2 & 0.025 \\
\hline \multicolumn{4}{|l|}{ New_tumor_event_type } \\
\hline Metastasis & 31 & 23 & \\
\hline Metastasis: recurrence & 3 & 1 & \\
\hline Primary & 2 & 1 & \\
\hline Recurrence & 17 & 12 & \\
\hline Recurrence: primary & & 1 & 0.907 \\
\hline \multicolumn{4}{|l|}{ Radiation_therapy } \\
\hline Non-radiation & 61 & 84 & \\
\hline Radiation & 25 & 19 & 0.122 \\
\hline \multicolumn{4}{|l|}{ History_of_neoadjuvant_treatment } \\
\hline No neoadjuvant & 188 & 187 & \\
\hline \multicolumn{4}{|l|}{ Therapy_type } \\
\hline Ancillary: chemotherapy & 19 & 13 & \\
\hline Chemotherapy & 63 & 65 & \\
\hline Chemotherapy: other. Specify in notes & 1 & & \\
\hline Chemotherapy: & & 1 & \\
\hline Chemotherapy: targeted molecular therapy & & 1 & 0.406 \\
\hline
\end{tabular}

\section{Discussion}

New cases of gastric cancer are increasing, and gastric cancer ranks fifth among malignancies and fourth as regards mortality worldwide. Moreover, the development of targeted therapy in gastric cancer is more limited than those in non-small cell lung cancer, chronic myelogenous leukemia, and liver cancer. Although the HER-2 targeted pathway, vascular endothelial growth factor pathway, and immune checkpoints have been widely used, the overall prognosis of patients with gastric cancer has not been revolutionized. Cell proliferation is a basic strategy of targeted therapy, so its mechanism and relationship with immune regulation are clinically worth exploring.

NEKs are a group of proteins whose domains are identical to NIMA. Some NEKs were related to tumor progression, such as breast cancer and colorectal cancer. In this study, the results of the bioinformatic analysis showed that among NEKs, the expressions of NEK2, NEK6, and NEK7 are upregulated, whereas NEK3 and NEK7 are related to the poor prognosis of gastric cancer.
Thus, NEK7 was selected in this study as it shows differences in both expression levels and effects on prognosis.

The cGMP-PKG and Hedgehog signaling pathways could influence tumor cell fate determination and are closely related to the development of tumors [19-21]. According to Xiang et al., the cGMP-PKG pathway is related to gastric cancer caused by Helicobacter pylori [22]. Besides, Lv et al. showed that the cGMP-PKG pathway could enhance breast cancer stemness and metastasis [19]. The Hedgehog signaling pathway can promote tumor angiogenesis, metastasis, and stemness. Our data indicate that NEK7 participates in cancer cell proliferation and is related to the clinical stage as well as pathological grade. Moreover, NEK7 has a potential regulatory function in the cGMP-PKG pathway and Hedgehog signaling pathway.

Immune infiltration analysis shows that NEK7 is closely related to the infiltration of macrophages, especially M2 macrophage that could promote gastric cancer metastasis, cell proliferation, and tumor 

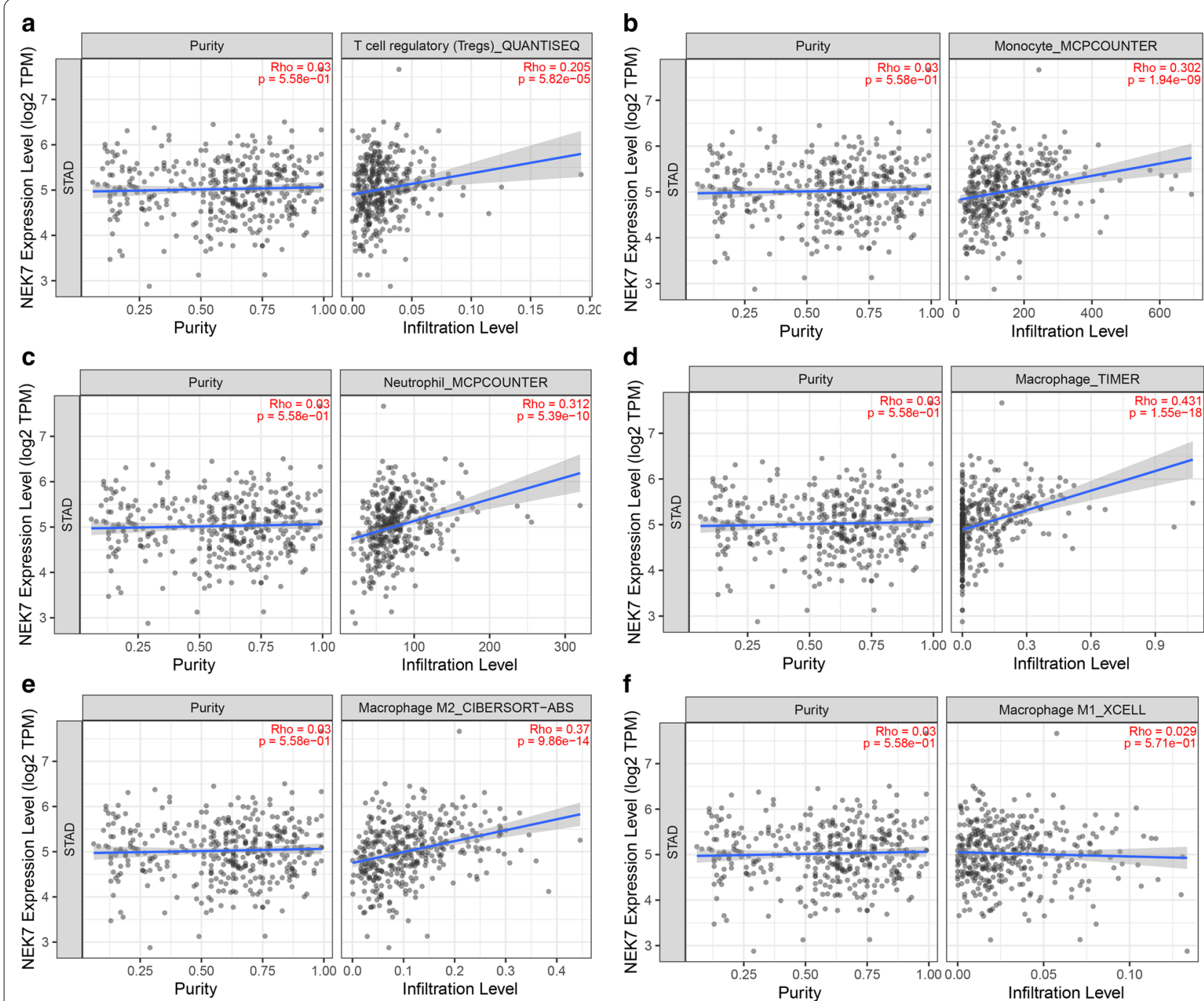

Fig. 3 The correlation between NEK7 and immune infiltration. a Tregs infiltration is positively related to the NEK7 expression level. b Monocyte infiltration is positively related to the NEK7 expression level. c Neutrophil infiltration is positively related to the NEK7 expression level. $\mathbf{d}$ Macrophage infiltration is positively related to the NEK7 expression level. e Macrophage M2 infiltration is positively related to the NEK7 expression level. f Macrophage M1 infiltration is negatively related to the NEK7 expression level

progression [23]. NEK7 could interact with NLRP3 and plays an important role in inflammatory response and determination of macrophage fate [24]. We hold the view that NEK7 could promote gastric cancer progression through not only regulation of cancer cell proliferation directly but also cell interaction, which could regulate immune infiltration and changes in immune cell subsets. In addition, GO and KEGG analyses indicate that NEK7 has a close relationship with several intercellular and matrix-related signaling pathways.

Ultimately, we revealed how NEK7 promotes gastric cancer proliferation and analyze the mechanism of promoting the progression of gastric cancer (Additional file 2). 


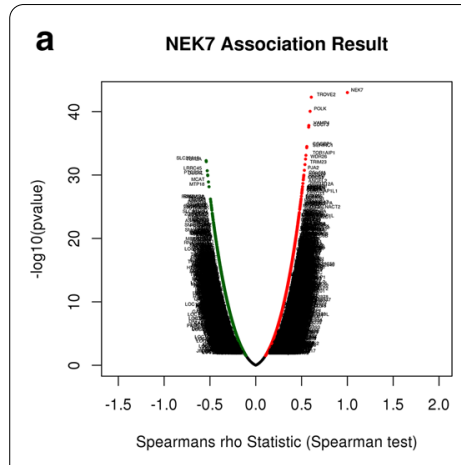

d

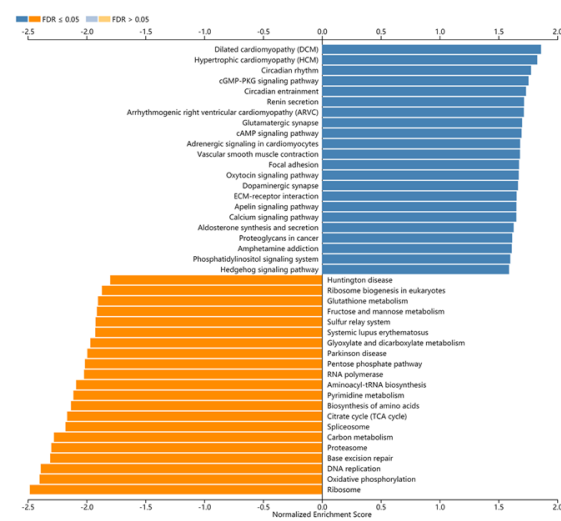

f Gene set: GO:0098742 ðcell-cell adhesion via plasma-membrane adhesion molecules
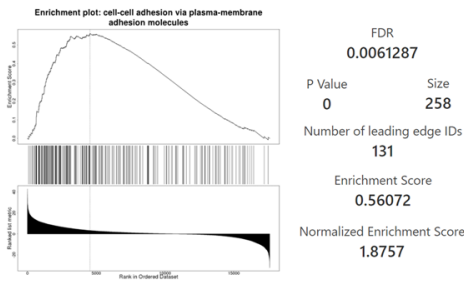

1.8757
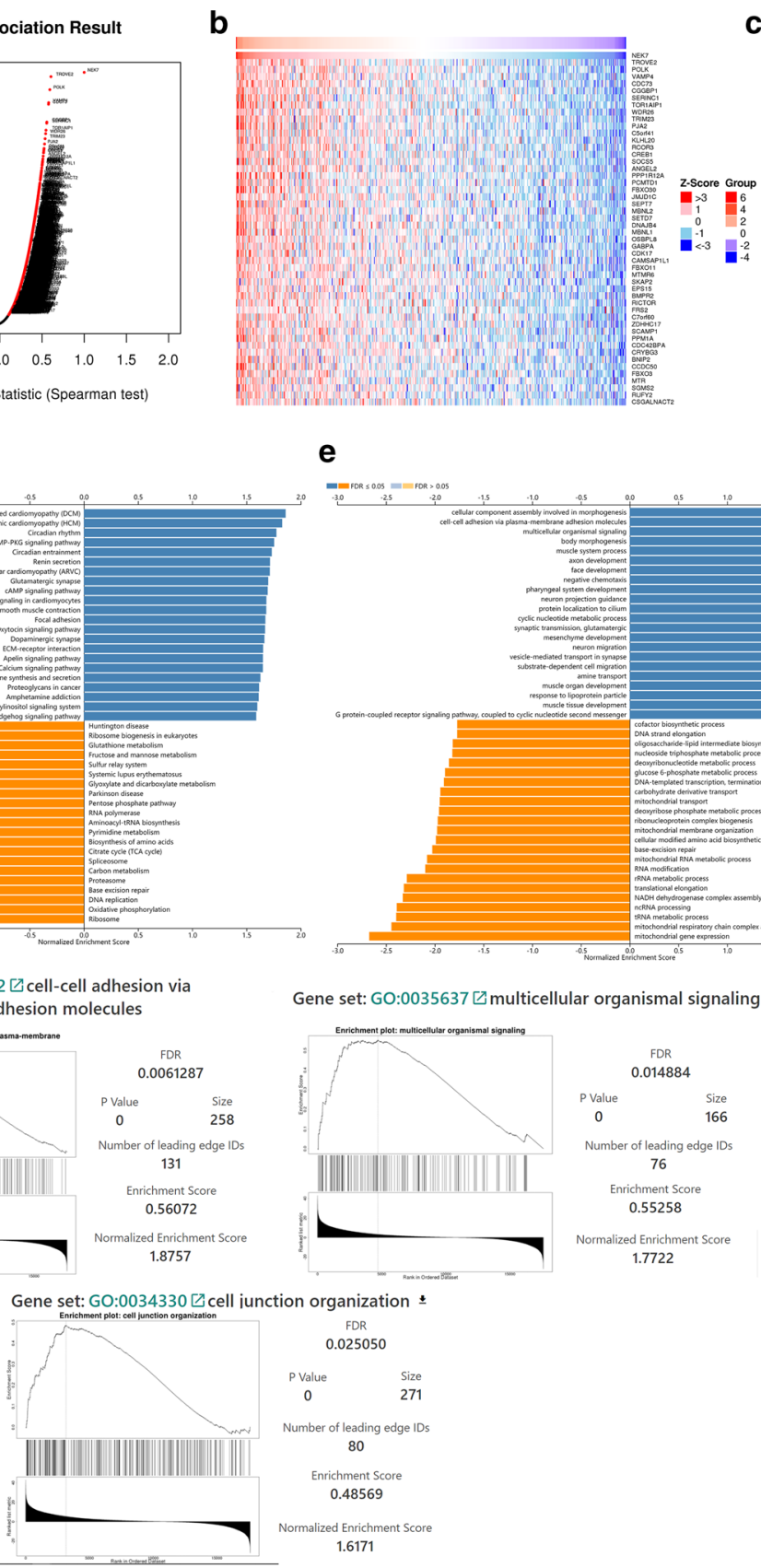

c

e

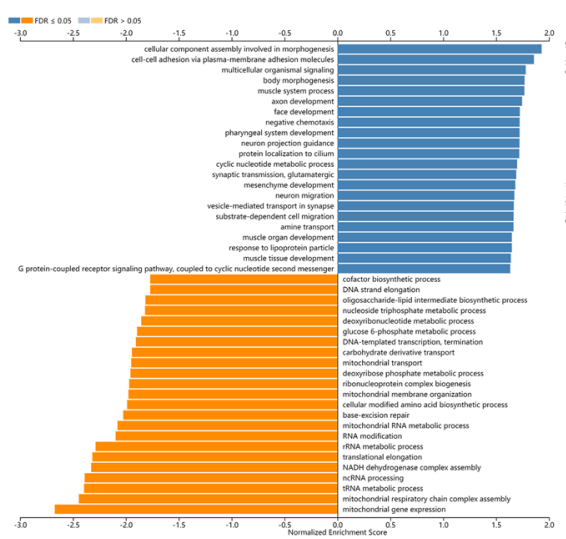

Gene set: GO:0035637 『multicellular organismal signaling *
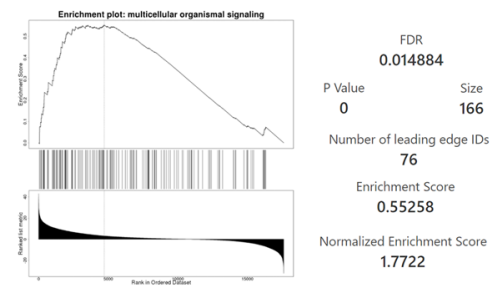

0.55258

Normalized Enrichment Score
1.7722

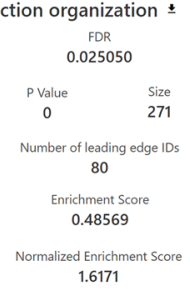

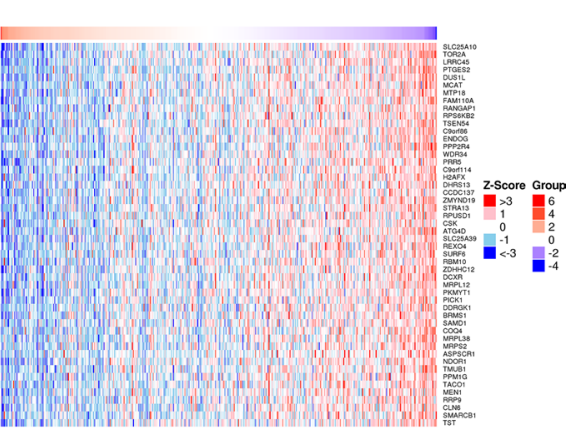

g Gene set: hsa04022EcGMP-PKG signaling pathway *

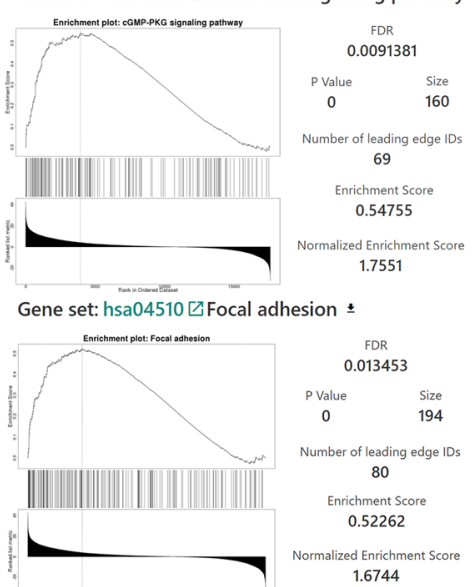

Gene set: hsa04512 『ECM-receptor interaction *

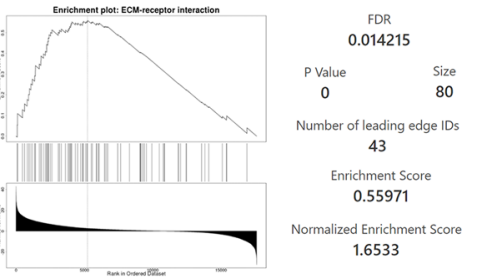

Gene set: hsa04340 [JHedgehog signaling pathway *
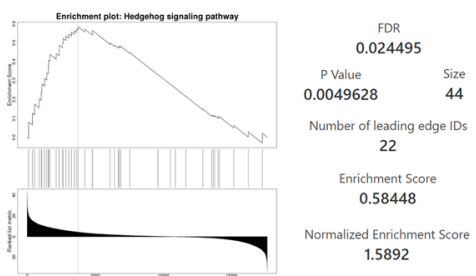

Fig. 4 Analysis of NEK7 and relative signaling pathways. a The volcano plot shows the genes associated with NEK7. b The heat map shows the first 50 pathways positively related to NEK7. c The heat map shows the first 50 pathways negatively related to NEK7. d Kyoto Encyclopedia of Genes and Genomes (KEGG) analysis of gene pathways associated with NEK7. e Gene ontology analysis of gene pathways associated with NEK7. $\mathbf{f}$ Gene ontology-biological processes analysis shows pathways associated with NEK7. g Gene set enrichment analysis (GSEA) shows the relationship between NEK7 and CGMP-PKG signaling pathway, focal adhesion, extracellular matrix (ECM)-receptor interaction, and Hedgehog signaling pathway 


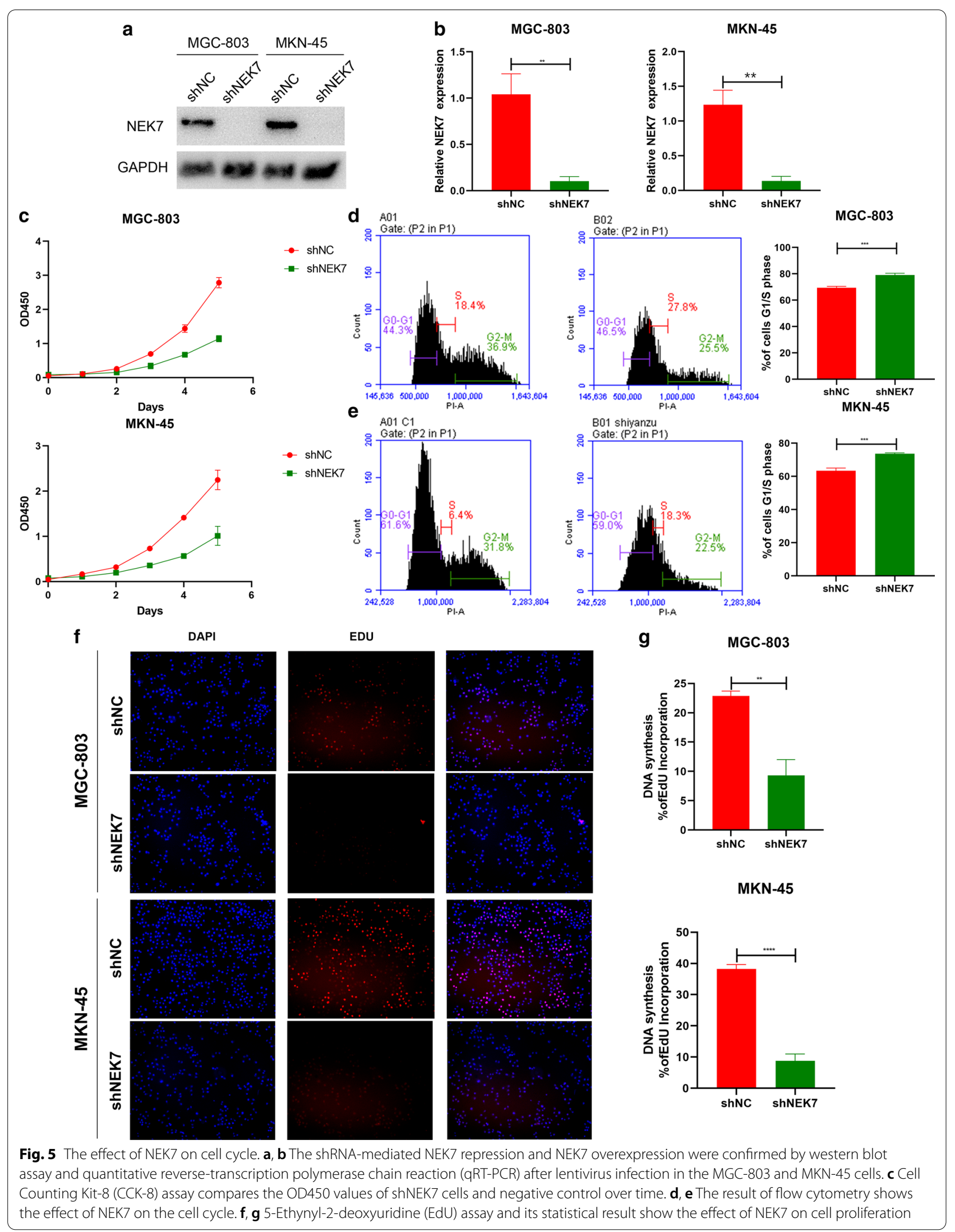




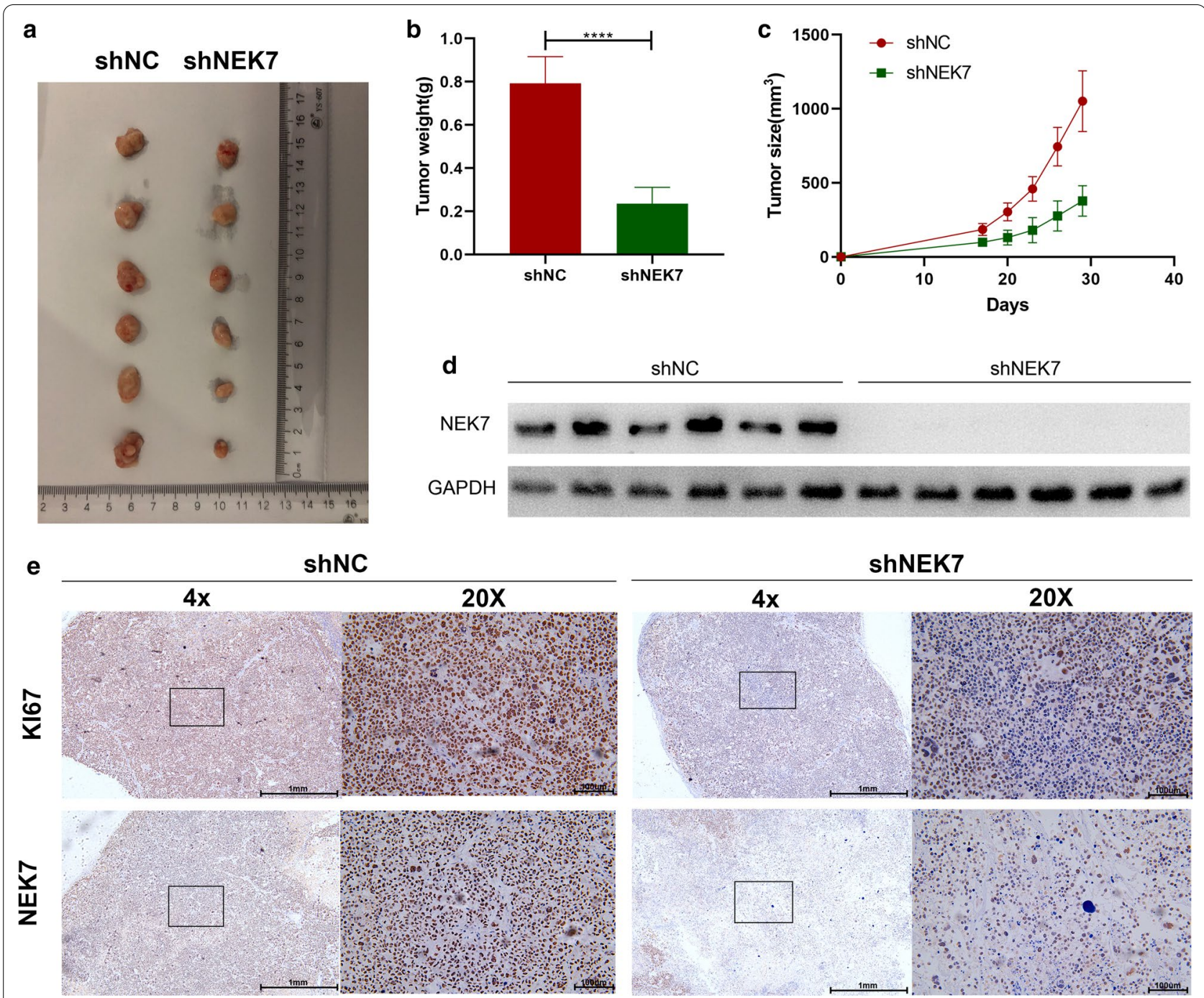

Fig. 6 The tumor inhibition caused by absence of NEK7 in vitro. a-c NEK7 knockdown effectively suppressed subcutaneous tumor growth of gastric cancer in nude mice, and the tumor weight and size were quantitatively analyzed. $\mathbf{d}$ Western blot assay confirmed the expression of NEK7 in the subcutaneous tumor. e IHC (NEK7) stained and IHC (KI67) paraffin-embedded sections obtained from the MKN45-shNC and MKN45-shNEK7 subcutaneous tumors

\section{Abbreviations}

NIMA: Never-in-mitosis A; GC: Gastric cancer; EdU: 5-Ethynyl-2-deoxyuridine; CCK-8: Cell counting kit-8; STAD: Stomach adenocarcinoma; RIP: RNA immunoprecipitation; acRIP: Ac4C-RNA immunoprecipitation; TCGA: The cancer genome atlas; GEPIA: Gene expression profiling and interactive analyses; shRNA: Short hairpin RNA; qRT-PCR: Quantitative real-time PCR; WB: Western blot; IHC: Immunohistochemistry; GO-BP: Gene ontology biological process; GSEA: Gene set enrichment analysis.

\section{Supplementary Information}

The online version contains supplementary material available at https://doi. org/10.1186/s12935-021-02148-8.
Additional file 1: Fig. S1. NEK7 effect on relative signaling pathwayrelated proteins. a. Expression levels of cell cycle-related proteins (CDK4 and CCND2), Hedgehog signaling pathway-related proteins (CCND2 and KIF3A), and CGMP-PKG signaling pathway-related proteins (AKT3 and PRKG1) with shNC and shNEK7 detected by western blot assay. b. Gene expression profiling interactive analysis (GEPIA) of the correlation among NEK7 and cell cycle-related proteins (CDK4 and CCND2), Hedgehog signaling pathway-related proteins (CCND2 and KIF3A), and CGMP-PKG signaling pathway-related proteins (AKT3 and PRKG1).

Additional file 2. Original data. 
Acknowledgements

We thank Mr. Yigan Zhang for his expert technical assistance.

\section{Authors' contributions}

$W-L J, W-Z Y, Y-K L$, and $X-R Z$ conceived and designed the study. $Y-K L, X-R Z$ and $Y Z$ conducted the experiments. $Y-K L$ and $X-R Z$ performed the statistical analysis of the pathological data and drafted the manuscript. All authors have read and approved the final manuscript.

\section{Funding}

The study was partially supported by the National Key Research and Development Program of China (no.2017FYA0205302) to Wei-Lin Jin.

\section{Availability of data and materials}

The datasets used and/or analyzed during the current study can be acquired from the corresponding author upon reasonable request.

\section{Declarations}

\section{Ethics approval and consent to participate}

This study was approved by the Ethics Committee of the First Hospital of Lanzhou University (LDYYLL2021-179). GC tissue microarrays were purchased from Shanghai Outdo Biotech.

\section{Competing interests}

The authors declare that they have no competing interests.

\section{Author details}

'Wenzhou Medical University, Wenzhou 325035, People's Republic of China. ${ }^{2}$ The First School of Clinical Medicine, Lanzhou University, Lanzhou 730000, People's Republic of China. ${ }^{3}$ Medical Pioneer Innovation Center, The First Hospital of Lanzhou University, Lanzhou 730000, People's Republic of China. ${ }^{4}$ Department of General Surgery, The First Hospital of Lanzhou University, Lanzhou 730000, People's Republic of China. ${ }^{5}$ Institute of Cancer Neuroscience, The First Hospital of Lanzhou University, Lanzhou 730000, People's Republic of China. 'SChool of Basic Medical Science, Lanzhou University, Lanzhou 730000, People's Republic of China.

Received: 2 May 2021 Accepted: 13 August 2021

Published online: 21 August 2021

\section{References}

1. Bray F, Ferlay J, Soerjomataram I, Siegel RL, Torre LA, Jemal A. Global cancer statistics 2018: GLOBOCAN estimates of incidence and mortality worldwide for 36 cancers in 185 countries. CA Cancer J Clin. 2018;68(6):394-424. https://doi.org/10.3322/caac.21492 (Epub 2018 Sep 12. Erratum in: CA Cancer J Clin. 2020 Jul;70(4):313. PMID: 30207593).

2. Grallert B, Boye E. The Gcn2 kinase as a cell cycle regulator. Cell Cycle. 2007;6(22):2768-72. https://doi.org/10.4161/cc.6.22.4933 (Epub 2007 Aug 22. PMID: 17986863).

3. Morris NR. Mitotic mutants of Aspergillus nidulans. Genet Res. 1975;26(3):237-54. https://doi.org/10.1017/s0016672300016049 (PMID: 773766).

4. Oakley BR, Morris NR. A mutation in Aspergillus nidulans that blocks the transition from interphase to prophase. J Cell Biol. 1983;96(4):1155-8. https://doi.org/10.1083/jcb.96.4.1155.PMID:6339527;PMCID:PMC2112314.

5. Fry AM, Bayliss R, Roig J. Mitotic regulation by NEK kinase networks. Front Cell Dev Biol. 2017;1(5):102. https://doi.org/10.3389/fcell.2017.00102. PMID:29250521;PMCID:PMC5716973.

6. Matossian MD, Wells Cl, Zuercher WJ, Collins-Burow BM, Drewry DH, Burow ME. Targeting never-in-mitosis-a related kinase 5 in cancer: a review. Curr Med Chem. 2021. https://doi.org/10.2174/092986732866621 0322101749 (Epub ahead of print. PMID: 33749548).

7. Sun Z, Gong W, Zhang Y, Jia Z. Physiological and pathological roles of mammalian NEK7. Front Physiol. 2020;7(11): 606996. https://doi.org/10. 3389/fphys.2020.606996.PMID:33364979;PMCID:PMC7750478.

8. Cullati SN, Kabeche L, Kettenbach AN, Gerber SA. A bifurcated signaling cascade of NIMA-related kinases controls distinct kinesins in anaphase. J Cell Biol. 2017;216(8):2339-54. https://doi.org/10.1083/jcb.201512055 (Epub 2017 Jun 19. PMID: 28630147; PMCID: PMC5551695).

9. Salem H, Rachmin I, Yissachar N, Cohen S, Amiel A, Haffner R, Lavi L, Motro B. Nek7 kinase targeting leads to early mortality, cytokinesis disturbance and polyploidy. Oncogene. 2010;29(28):4046-57. https://doi.org/10.1038/ onc.2010.162 (Epub 2010 May 17 PMID: 20473324).

10. Xu J, Lu L, Li L. NEK7: a novel promising therapy target for NLRP3related inflammatory diseases. Acta Biochim Biophys Sin (Shanghai). 2016:48(10):966-8. https://doi.org/10.1093/abbs/gmw080 (Epub 2016 Aug 25 PMID: 27563009).

11. Sharif H, Wang L, Wang WL, Magupalli VG, Andreeva L, Qiao Q, Hauenstein AV, Wu Z, Núñez G, Mao Y, Wu H. Structural mechanism for NEK7-licensed activation of NLRP3 inflammasome. Nature. 2019;570(7761):338-43. https://doi.org/10.1038/s41586-019-1295-z (Epub 2019 Jun 12. PMID: 31189953; PMCID: PMC6774351).

12. Cai $H$, Wang $P$, Zhang $B$, Dong $X$. Expression of the NEK7/NLRP3 inflammasome pathway in patients with diabetic lower extremity arterial disease. BMJ Open Diabetes Res Care. 2020;8(2): e001808. https://doi.org/ 10.1136/bmjdrc-2020-001808.PMID:33323459;PMCID:PMC7745315.

13. Zhang Y, Lv X, Hu Z, Ye X, Zheng X, Ding Y, Xie P, Liu Q. Protection of Mcc950 against high-glucose-induced human retinal endothelial cell dysfunction. Cell Death Dis. 2017;8(7): e2941. https://doi.org/10.1038/ cddis.2017.308.PMID:28726778;PMCID:PMC5550855.

14. Ma ZZ, Sun HS, Lv JC, Guo L, Yang QR. Expression and clinical significance of the NEK7-NLRP3 inflammasome signaling pathway in patients with systemic lupus erythematosus. J Inflamm (Lond). 2018;3(15):16. https:// doi.org/10.1186/s12950-018-0192-9.PMID:30202244;PMCID:PMC6122698.

15. Lin Y, Luo T, Weng A, Huang X, Yao Y, Fu Z, Li Y, Liu A, Li X, Chen D, Pan H. Gallic acid alleviates gouty arthritis by inhibiting NLRP3 inflammasome activation and pyroptosis through enhancing Nrf2 signaling. Front Immunol. 2020;7(11): 580593. https://doi.org/10.3389/fimmu.2020.580593. PMID:33365024;PMCID:PMC7750458.

16. Eisa NH, Jilani Y, Kainth $K$, Redd P, Lu S, Bougrine O, Abdul Sater H, Patwardhan CA, Shull A, Shi H, Liu K, Elsherbiny NM, Eissa LA, El-Shishtawy MM, Horuzsko A, Bollag R, Maihle N, Roig J, Korkaya H, Cowell JK, Chadli A. The co-chaperone UNC45A is essential for the expression of mitotic kinase NEK7 and tumorigenesis. J Biol Chem. 2019;294(14):5246-60. https://doi.org/10.1074/jbc.RA118.006597 (Epub 2019 Feb 8. PMID: 30737284; PMCID: PMC6462532)

17. Zhang J, Wang L, Zhang Y. Downregulation of NIMA-related kinase-7 inhibits cell proliferation by inducing cell cycle arrest in human retinoblastoma cells. Exp Ther Med. 2018;15(2):1360-6. https://doi.org/10. 3892/etm.2017.5558 (Epub 2017 Nov 23. PMID: 29434721; PMCID: PMC5774400)

18. Zhou L, Wang Z, Xu X, Wan Y, Qu K, Fan H, Chen Q, Sun X, Liu C. Nek7 is overexpressed in hepatocellular carcinoma and promotes hepatocellular carcinoma cell proliferation in vitro and in vivo. Oncotarget. 2016;7(14):18620-30. https://doi.org/10.18632/oncotarget.7620.PMID: 26921196;PMCID:PMC4951314.

19. Lv Y, Wang $X$, Li X, Xu G, Bai Y, Wu J, Piao Y, Shi Y, Xiang R, Wang L. Nucleotide de novo synthesis increases breast cancer stemness and metastasis via cGMP-PKG-MAPK signaling pathway. PLoS Biol. 2020;18(11): e3000872. https://doi.org/10.1371/journal.pbio.3000872.PMID:33186350;PMCID: PMC7688141

20. Kong $X$, Wang JS, Yang H. Upregulation of IncRNA DARS-AS1 accelerates tumor malignancy in cervical cancer by activating CGMP-PKG pathway. J Biochem Mol Toxicol. 2021;35(6):1-11. https://doi.org/10.1002/jbt.22749 (Epub 2021 Feb 25 PMID: 33634536). 
21. Jiang J. Hedgehog signaling mechanism and role in cancer. Semin Cancer Biol. 2021. https://doi.org/10.1016/j.semcancer.2021.04.003 (S1044579X(21)00104-8. Epub ahead of print. PMID: 33836254)

22. Xiang T, Yuan C, Guo X, Wang H, Cai Q, Xiang Y, Luo W, Liu G. The novel ZEB1-upregulated protein PRTG induced by Helicobacter pylori infection promotes gastric carcinogenesis through the CGMP/PKG signaling pathway. Cell Death Dis. 2021;12(2):150. https://doi.org/10.1038/s41419021-03440-1.PMID:33542225;PMCID:PMC7862680.

23. Yang X, Cai S, Shu Y, Deng X, Zhang Y, He N, Wan L, Chen X, Qu Y, Yu S. Exosomal miR-487a derived from $\mathrm{m} 2$ macrophage promotes the progression of gastric cancer. Cell Cycle. 2021;20(4):434-44. https://doi.org/10. 1080/15384101.2021.1878326 (Epub 2021 Jan 31. PMID: 33522393; PMCID: PMC7894454)
24. Schmid-Burgk JL, Chauhan D, Schmidt T, Ebert TS, Reinhardt J, Endl E, Hornung $\vee$. A genome-wide CRISPR (clustered regularly interspaced short palindromic repeats) screen identifies NEK7 as an essential component of NLRP3 inflammasome activation. J Biol Chem. 2016;291(1):103-9. https:// doi.org/10.1074/jbc.C115.700492 (Epub 2015 Nov 9. PMID: 26553871; PMCID: PMC4697147).

\section{Publisher's Note}

Springer Nature remains neutral with regard to jurisdictional claims in published maps and institutional affiliations.
Ready to submit your research? Choose BMC and benefit from:

- fast, convenient online submission

- thorough peer review by experienced researchers in your field

- rapid publication on acceptance

- support for research data, including large and complex data types

- gold Open Access which fosters wider collaboration and increased citations

- maximum visibility for your research: over 100M website views per year

At BMC, research is always in progress.

Learn more biomedcentral.com/submissions 